\title{
Factors affecting voice quality in early glottic cancer before and after radiotherapy
}

\author{
Jana Mekis ${ }^{1}$, Primoz Strojan ${ }^{1,2}$, Irena Hocevar Boltezar ${ }^{1,3}$ \\ ${ }^{1}$ Faculty of Medicine, University of Ljubljana, Ljubljana, Slovenia \\ ${ }^{2}$ Institute of Oncology Ljubljana, Ljubljana, Slovenia \\ ${ }^{3}$ University Department of Otorhinolaryngology and Cervicofacial Surgery, University Medical Centre, Ljubljana, Slovenia
}

Radiol Oncol 2019; 53(4): 459-464

Received 25 August 2019

Accepted 17 September 2019

Correspondence to: Prof. Irena Hočevar Boltežar, M.D., Ph.D., University Department of Otorhinolaryngology and Cervicofacial Surgery, Zaloška cesta 2, 1000 Ljubljana, Slovenia; Phone: +386 41958 336; Fax: +386 152241 08; E-mail: boltezar.irena@gmail.com or irena.hocevar-boltezar@mf.uni-lj.si

Disclosure: No potential conflicts of interest were disclosed.

Background. Radiotherapy (RT) is a successful mode of treatment for early glottic cancer. The aim of the study was to assess voice quality both before and 3 months after successful RT using multimodal methods while also identifying the factors affecting it.

Patients and methods. In 50 patients with $\mathrm{Tl}$ glottic carcinoma, the subjective (patients' assessment of voice quality [VAS], Voice Handicap Index [VHI] questionnaire, phoniatricians' assessment using the grade/roughness/ breathiness [GRB] scale), and objective assessments (fundamental laryngeal frequency $\left[F_{0}\right]$ jitter, shimmer, maximum phonation time [MPT]) of voice quality were performed before RT and 3 months post-RT. The data on gender, age, extent of the tumors, biopsy types, smoking, local findings, and RT were obtained from the medical documentation. Results. Three months after the treatment, VAS, VHI, G and R scores, $F_{0}$, and MPT significantly improved in comparison with their assessment prior to treatment. Before the treatment, the involvement of the anterior commissure significantly deteriorated jitter $(p=0.044)$ and the involvement of both vocal folds deteriorated jitter $(p=0.003)$ and shimmer $(p$ $=0.007)$. After the RT, $F_{0}$ was significantly higher in the patients with repeated biopsy than in the others $(p=0.047)$. In patients with post-RT changes, the B score was significantly higher than in those without post-RT changes $(p=0.029)$. Conclusions. Voice quality already significantly improved three months after the treatment of glottic cancer. The main reason for the decreased voice quality prior to treatment is the tumor's extent. Post-RT laryngeal changes and repeated biopsies caused more scarring on vocal folds adversely influencing voice quality after the treatment.

Key words: glottic cancer; radiotherapy; subjective assessment; acoustic analysis; aerodynamic measurement

\section{Introduction}

Radiotherapy (RT) and transoral endoscopic laser surgery are the treatments of choice for early (T1N0M0) glottic cancer. ${ }^{1,2}$ In these cases, the aim of treatment is not only the eradication of the tumor, but also the preservation of larynx functions. ${ }^{3}$ The choice between the two treatment options should be adjusted for each patient based on tumor characteristics, her/his medical condition and personal preferences, anticipated treatment morbidity with their quality of voice as the priority, and, additionally, based on costs. ${ }^{2}$ Even though the studies showed that RT is more expensive than endoscopic laser surgery, RT still remains the preferred treatment modality in many oncological centres due to the presumably better voice quality outcome. ${ }^{1,4,5}$ Voice quality has a significant effect on patients' quality of life as it plays an important role in patients' communication with others. ${ }^{6}$ It also defines the time when the patient is unable to work, especially for those who use their voice in their profession. Therefore, it is important for them to have good voice quality as soon as possible following treatment. 
There are several factors that influence the voice outcome following the RT treatment. Such factors include smoking during and after the treatment, talking during the treatment, the type and extent of the biopsy, extent and depth of the invasion of the tumor, the patient's age, total radiation dose and its distribution in the larynx, RT fractionation pattern, and also RT-related side effects such as oedema and fibrosis. ${ }^{7-10}$ Different subjective and objective methods are available for the assessment of voice quality. ${ }^{3}$ There are almost no studies focusing on the early improvement of one's voice following RT treatment.

The aims of the present study were: (i) to assess changes in voice quality three months after RT using subjective and objective methods of evaluation; (ii) to identify possible factors influencing voice quality before and after the treatment of early glottic cancer.

\section{Patients and methods}

\section{Patients}

In the prospective study, 77 consecutive patients who had been diagnosed at a tertiary centre between 2006-2012 with glottic squamous cell carcinoma of stage T1N0M0 and who had been treated with curative-intent RT were included. All patients signed written informed consent after receiving detailed information concerning the study and related examinations. In three patients, a local recurrence was diagnosed during a followup, and 24 patients did not attend all planned follow-up visits. Therefore, the study group consisted of 50 patients.

The characteristics of patients with information about smoking, the extent of tumors in the glottis, vocal fold closure during phonation, biopsy types (punch mucosal biopsy or deep excisional biopsy, possible repeated biopsy), and RT details were collected from the medical documentation. After treatment, patients were followed-up at 3 months in order to assess the improvement of their voices and the handicaps related to their voice qualities.

\section{Radiotherapy}

All the patients were treated with RT in the supine position and immobilized with a thermoplastic mask. They were irradiated with a continuous-course irradiation using one daily fraction of 2.25 Gy up to the median total dose of $63 \mathrm{~Gy}$ (range, 58.5-65.25 Gy; all but 5 patients received 63 Gy), delivered over 36 to 49 days (median, 39 days; mean $39.82 \pm 2.56$ days). MV photon beams and computer-generated dosimetry were employed in all patients. The dose was prescribed to a planning target volume (PTV) encompassing involved vocal cord(s) with ipsilateral arytenoid(s), the parapharyngeal space, and anterior commissure, up to the most cranial extent of the arytenoid cartilage superiorly and $1-1.5 \mathrm{~cm}$ below the level of the true vocal cord inferiorly.

\section{Evaluation of laryngeal function and voice quality}

The examinations were performed before RT and 3 months after irradiation.

\section{Subjective phoniatrician's and patient's evaluation}

A perceptive analysis of voice quality during spontaneous speech by a phoniatrician was performed using the GRB score (grade [G], roughness [R], breathiness $[\mathrm{B}]$; graded from 0 to $3[0=$ not present, 3 = severe disorder]) before and three months after the treatment.

Patients assessed their voice quality according to the visual analogue scale (VAS, from 0 to $100 \%$ ). They also completed the Voice Handicap Index questionnaire (VHI), which is showing the influence of the patients' voice on their lives. ${ }^{12}$ A score above 18 was considered characteristic for a clinical voice disorder. ${ }^{13}$

In order to evaluate the post-radiation mucosal changes (tissue defects, atrophy, fibrosis, oedema; graded from 0 to $3[0=$ no changes, $3=$ severe changes]), closure between the vocal folds (complete, incomplete), and the mobility of the vocal folds (normal, impaired, immobile), a stroboscopy was performed 3 months after the RT.

\section{Objective acoustic analysis of voice samples and aerodynamic measurement}

An acoustic analysis of three samples of the vowel /a/ at the most comfortable pitch and volume, employing the Multi-Dimensional Voice Program (KayPentax ${ }^{\circledR}$, USA), along with a measurement of the maximum phonation time (MPT) were performed. The mean values of fundamental frequency $\left(\mathrm{F}_{0}, \mathrm{~Hz}\right)$, pitch perturbation (jitter, \%) and amplitude perturbation (shimmer, \%) of all three voice samples were used for further analysis. 


\section{Ethical consideration and statistics}

The study protocol was in accordance with the Helsinki declaration and requirements accepted by the Republic of Slovenia National Medical Ethics Committee. Analyses were performed using the SPSS version 22.0 (SPSS Inc., Chicago, IL, USA). All statistical tests were two-sided and a p-value of $\leq$ 0.05 was considered statistically significant.

The results of the perceptive assessment of the patient's and phoniatrician's voice, VHI questionnaires, the acoustic analysis of voice samples, and MPT were compared both pretreatment and three months after RT. The normality testing of numerical data was done by the Shapiro-Wilk test, which was presented as mean \pm standard deviation (SD) or as median (range). For a paired comparison of numerical data, the paired t-test or non-parametric Wilcoxon signed-rank test was employed. The relationship between certain factors (smoking before and after treatment, the extent of the tumor, involvement of anterior commissure, type of biopsy, repeated biopsy, post-radiation mucosal changes), the results of subjective evaluations (VAS, VHI, GRB scores), the objective measurements $\left(\mathrm{F}_{0}\right.$, jitter, shimmer, MPT), t-test or non-parametric Mann Whitney test, and the bivariate correlation (age) were used.

\section{Results}

In the study group, there were 44 men and 6 women, between 32 and 85 years of age. Ten patients were under 56 years of age and 21 subjects were under 61 years of age. The tumor was limited to one vocal fold in 40 patients. In seven cases, the anterior commissure was involved. Data on type of biopsy was not available for one patient. The patients' characteristics are shown in Table 1.

Before treatment, 30 patients were active smokers and 12 patients stopped smoking more than 6 months before the beginning of treatment. Four patients did not answer the question about smoking. See Table 1. After the treatment, only two patients were still smoking.

The patients' assessment of voice quality on VAS and the results of VHI were significantly improved three months after the treatment in comparison to their evaluations before treatment. Before treatment, all the patients had hoarse voices according to the phoniatrician's assessment $(G>0)$. After the treatment, the phoniatrician's assessment of $G$ and $\mathrm{R}$ also showed significantly better voice quality (Table 2).
TABLE 1. Characteristics of the patients in the study $(N=50)$

\begin{tabular}{lc}
\hline Patients' characteristic & Data \\
\hline Gender (male/female) & 44 / 6 \\
Age (mean/standard deviation, years) & $62.48 \pm 9.99$ \\
Smoking (before treatment) & \\
- non-smokers & 4 \\
- smokers & 30 \\
- ex-smokers* & 12 \\
- unknown & 4 \\
Type of biopsy & 13 \\
- punch biopsy & 36 \\
- excisional biopsy & 1 \\
- unknown & 15 \\
Repeated biopsy & \\
Glottic cancer & 40 \\
- one vocal fold & 10 \\
- both vocal folds & 7 \\
- anterior commissure involvement & \\
\hline
\end{tabular}

* patients stopped smoking more than 6 months before the beginning of the treatment

TABLE 2. Comparison of the subjective and objective assessments of vocal fold function and voice quality $(N=50)$

\begin{tabular}{|c|c|c|c|}
\hline Parameter & $\begin{array}{c}\text { Before } \\
\text { treatment } \\
\text { (mean / SD) }\end{array}$ & $\begin{array}{c}3 \text { months after } \\
\text { treatment } \\
\text { (mean / SD) }\end{array}$ & $\mathbf{P}$ \\
\hline $\begin{array}{l}\text { Subjective phoniatrician's } \\
\text { assessment } \\
\text { - Grade Score } \\
\text { - Roughness Score } \\
\text { - Breathiness Score }\end{array}$ & $\begin{array}{l}1.95 / 0.71 \\
1.91 / 0.71 \\
0.05 / 0.21\end{array}$ & $\begin{array}{l}1.35 / 0.61 \\
1.28 / 0.63 \\
0.02 / 0.15\end{array}$ & $\begin{array}{l}0.000 \\
0.000 \\
0.324\end{array}$ \\
\hline $\begin{array}{l}\text { Patient's assessment of voice } \\
\text { quality (VAS; \%) }\end{array}$ & $44.67 / 22.37$ & $70.54 / 24.22$ & 0.000 \\
\hline $\begin{array}{l}\text { Voice Handicap Index } \\
\text { Score }\end{array}$ & $49.67 / 30.09$ & $22.46 / 23.56$ & 0.000 \\
\hline $\begin{array}{l}\text { Post-radiation mucosa chang } \\
\text { - not present } \\
\text { - slight } \\
\text { - moderate } \\
\text { - not assessed }\end{array}$ & $\begin{array}{l}1 \\
1 \\
1 \\
1\end{array}$ & $\begin{array}{c}2 \\
40 \\
2 \\
6\end{array}$ & \\
\hline $\begin{array}{l}\text { Vocal folds' mobility } \\
\text { - normal } \\
\text { - impaired }\end{array}$ & 50 & $\begin{array}{c}47 \\
3\end{array}$ & \\
\hline $\begin{array}{l}\text { Vocal fold closure } \\
\text { - complete } \\
\text { - incomplete } \\
\text { - not assessed }\end{array}$ & $\begin{array}{c}1 \\
49\end{array}$ & $\begin{array}{c}8 \\
35 \\
7\end{array}$ & 0.036 \\
\hline $\mathrm{F}_{0}(\mathrm{~Hz})$ & 187.63 / 80.38 & $152.71 / 32.46$ & 0.000 \\
\hline Jitter (\%) & 3.79 / 3.47 & $2.84 / 4.11$ & 0.148 \\
\hline Shimmer (\%) & $7.98 / 5.79$ & $6.64 / 5.17$ & 0.178 \\
\hline Maximum phonation time (s) & $14.06 / 7.21$ & $18.98 / 7.8$ & 0.032 \\
\hline
\end{tabular}

$F_{0}=$ fundamental laryngeal frequency 
At three months post-RT, the post-radiation mucosal changes of the vocal folds were seen in all but two patients (Figures 1 and 2). In six patients, an assessment of the vocal cords was not possible because of an adduction of the ventricular folds above them during phonation. The vocal fold closure became complete in 7 patients after the successful treatment of glottic cancer (Table 2).

After RT, the mean $\mathrm{F}_{0}$ decreased to a more acceptable value regarding gender. The perturbation of pitch (jitter) and amplitude (shimmer) became lower, exhibiting less voice instability although, compared to pre-RT values, the difference was not significant. Also, MPT was found significantly longer after RT (Table 2).

Three months after the RT treatment, the patients expressed considerable satisfaction with their voices as $26(52 \%)$ of them had VHI score less than 19 compared to only $9(18 \%)$ patients with a VHI score less than 19 during their pre-RT evaluation $(\mathrm{p}=0.000)$. Twenty $(40 \%)$ patients assessed their voice quality as $80 \%$ of a normal voice or higher. On the other hand, the phoniatrician perceptively detected normal voice $(\mathrm{G}$ score $=0)$ in only 2 patients after therapy. In all patients, at least one of the objective parameters of voice quality $\left(\mathrm{F}_{0}\right.$ jitter, shimmer, MPT) remained abnormal.

The relationship between different factors with a possible impact on voice quality (i.e. gender, age, extent of the tumor, involvement of the ante-

TABLE 3. Significant associations between some factors possibly affecting voice quality and the results of the subjective and objective vocal quality assessment in patients with early glottis cancer $(\mathrm{N}=50)$

\begin{tabular}{|c|c|c|c|}
\hline Parameter & $\begin{array}{l}\text { Present } \\
\text { (mean/ SD) }\end{array}$ & $\begin{array}{l}\text { Not present } \\
\text { (mean/ SD) }\end{array}$ & $\mathbf{P}$ \\
\hline $\begin{array}{l}\text { Gender } \\
\text { - } F_{0} \text { before therapy (male) } \\
-F_{0} \text { before therapy (female) }\end{array}$ & $178.91 / 45.05$ & $240.17 / 44.48$ & 0.001 \\
\hline $\begin{array}{l}\text { - } F_{0} \text { after therapy (male) } \\
\text { - } F_{0} \text { before therapy (female) }\end{array}$ & $145.00 / 25.20$ & $209.80 / 21.41$ & 0.000 \\
\hline $\begin{array}{l}\text { Anterior commissure involvement } \\
\text { - jitter before therapy }\end{array}$ & $5.39 / 2.74$ & $3.52 / 3.53$ & 0.044 \\
\hline $\begin{array}{l}\text { Tumor on both vocal folds } \\
\text { - jitter before therapy } \\
\text { - shimmer before therapy }\end{array}$ & $\begin{array}{l}7.21 / 5.91 \\
12.74 / 6.91\end{array}$ & $\begin{array}{l}3.02 / 2.07 \\
7.18 / 5.02\end{array}$ & $\begin{array}{l}0.003 \\
0.007\end{array}$ \\
\hline $\begin{array}{l}\text { Repeated biopsy } \\
\text { - } F_{0} \text { after therapy }\end{array}$ & $200.60 / 46.77$ & $182.94 / 51.96$ & 0.047 \\
\hline $\begin{array}{l}\text { Post-radiation changes } \\
\text { - maximum phonation time after } \\
\text { therapy } \\
\text { - Breathiness score after therapy }\end{array}$ & $\begin{array}{l}18.39 / 7.55 \\
0.02 / 0.15\end{array}$ & $\begin{array}{c}30.00 / 2.82 \\
0\end{array}$ & $\begin{array}{l}0.039 \\
0.029\end{array}$ \\
\hline $\begin{array}{l}\text { Complete vocal fold closure during } \\
\text { phonation } \\
\text { - maximum phonation time after } \\
\text { therapy }\end{array}$ & 25.29 / 8.71 & $17.84 / 7.04$ & 0.000 \\
\hline
\end{tabular}

$F_{0}=$ fundamental laryngeal frequency rior commissure, type of biopsy, repeated biopsy, smoking before and after therapy, post-radiation mucosal changes, impaired vocal fold mobility, incomplete vocal fold closure during vibration) and their influence on the subjective and objective parameters of voice assessment (VAS, VHI, GRB, $\mathrm{F}_{0}$ jitter, shimmer, MPT) before and 3 months after RT were also analysed. Only the statistically significant differences are presented in Table 3. Age, type of biopsy, and smoking did not significantly affect the results of subjective and objective voice quality evaluations and laryngeal function.

\section{Discussion}

In the present study, a significant improvement of voice quality was found three months after RT treatment for early glottic cancer when assessed subjectively by the patients (VAS, VHI) and by the phoniatrician (GR scale) or by objective methods (F0, MPT). After successful treatment, more than one half of the patients $(52 \%)$ demonstrated VHI scores typical for subjects without voice problems. However, normal voice quality was only detected in two patients by the phoniatrician's perceptive evaluation.

We evaluated voice quality through several subjective and objective methods. The patient's subjective assessments showed more favourable results than the phoniatrician's and the objective ones. Still, the subjective evaluations showed more improvement than the objective ones. One of the reasons could be the methodology of acoustic analysis and aerodynamic measurements. In both cases, only voice samples are assessed, whereas the patient (or phoniatrician) evaluates voices during everyday communication and not just voice samples.

We noticed a significant improvement in the G and $\mathrm{R}$ components of the GRB evaluation recorded by the phoniatrician at three months post-RT. Marciscano et al. report a significant improvement in voice quality according to the GRBAS composite score across the first four months after the RT. ${ }^{14}$ In our study, we only decided to carry out the assessment of the individual parameters, $G$, $\mathrm{R}$, and B. Therefore, a complete comparison with Marciscano's study cannot be done as we can merely compare trends in the change of individual parameters. In any case, both studies are among a few, rare studies that assessed voice quality in the first months following the end of the RT.

According to the patients' assessment, voice quality on VAS significantly improved after RT. 
$40 \%$ of the patients assessed their voice as $80 \%$ of a normal voice or even better. The VHI after RT gave even better results. More than one half of the patients $(52 \%)$ gained a score of 18 or lower. In a review paper of several translations of $\mathrm{VHI}$ in different languages, the values between 12 and 20 were found as cut-off points to distinguish between subjects with normal and pathological voices. The authors suggest that any VHI value above 18 is a sign of strong possibility of a clinical voice problem..$^{13}$ According to this recommendation, we decided to choose 19 points as the cut-off point. Despite favourable patient assessments of voice quality and its impact on their handicaps in their every-day lives, the phoniatrician detected normal voices in only two patients. We believe that the patients valuated their post-RT voice in comparison with the voice before the treatment. The phoniatrician tried to assess voices according to the accepted standards without being influenced by or without experience of the handicap of the pre-treatment voice quality.

The cause for a hoarse voice in a patient with early vocal fold cancer is the tumor itself. It disables normal vocal fold vibration and the completeness of the closure between them. Tumors affecting both vocal folds and/or anterior commissure cause more irregular vibrations of vocal folds and a less stable voice (increased jitter and shimmer). Following successful RT, the tumor disappears, which results in the scarring of the affected vocal fold; the mucosa of one or both vocal folds can become atrophic and/or swollen. The fibrotic transformation of tissues only at the site of the previous tumor or larger part/whole larynx with post radiation changes to the laryngeal joints, muscles, and nerves can result in the progressive impairment of mobility of one or both vocal folds. ${ }^{15-17}$ In our study, videoendostroboscopies showed post-radiation changes in all but two patients and impaired mobility of the affected vocal fold(s) was detected in three patients. Other authors also reported changes in the vocal folds' mobility after RT for early glottis cancer. Marciscano et al. found a significant improvement in the mobility and vibration of the ipsilateral vocal cord and a significant worsening in the contralateral vocal cord more than four months after treatment. ${ }^{14}$

The vocal fold closure was only complete in one patient before therapy. After the tumor disappeared from the glottis, the closure became complete in eight patients. The mass of the vocal folds with tumors decreased and more regular and symmetrical vibration was possible. The phonation demanded less effort and less activation of the laryngeal muscles. These are likely the main reasons for the improvements in voice quality. The $\mathrm{F}_{0}$ decreased as less tension in the laryngeal muscles was necessary for phonation. The perturbation of pitch and amplitude decreased but these changes did not reach a level of statistical significance. Nevertheless, the post-radiation changes (fibrosis, atrophy, oedema, decreased mobility) appeared in a high proportion of irradiated patients and negatively influenced voice quality. In those patients with repeated biopsies during the diagnostic phase, the scarring was even more prominent thus causing thinner vocal folds which vibrated with higher frequency (higher $\mathrm{F}_{0}$ ). We expect that in these patients' postradiation, changes will continue to influence voice quality over the following months.

In our group, before the treatment, the mean $\mathrm{F}_{0}$ for men was higher (almost $179 \mathrm{~Hz}$ ) than the reported normal range $(80-160 \mathrm{~Hz}){ }^{18}$ After treatment, it decreased to a normal range $(145 \mathrm{~Hz})$. In women, $\mathrm{F}_{0}$ also decreased after $\mathrm{RT}$ but the values remained within normal range (i.e. before and after the treatment). On the contrary, Lombardo et al. reported no statistically significant difference in $\mathrm{F}_{0}$ after RT treatment. ${ }^{19}$ The impact of gender on $\mathrm{F}_{0}$ before and after therapy is expected and related to anatomical characteristics of the larynx. ${ }^{6}$

In the present study, jitter and shimmer showed a pathological instability of the voice in all the patients with glottic cancer. After the successful treatment, the values remained above normal thresholds. ${ }^{18}$ Van Gogh et al. objectively assessed the voice outcome in 39 patients with T1 glottic cancer before and up to 2 years after RT. Three months after the treatment, $\mathrm{F}_{0}$ significantly decreased in comparison with the values before treatment and jitter and shimmer showed a significant improvement. ${ }^{20}$ The exact values of jitter and shimmer cannot be compared between the two groups of patients because a different instrument was used in our study.

In addition, a significant improvement in the MPT was found in our patients 3 months after RT completion. The reason was the better closure of vocal folds during phonation. The breathy vocal characteristic was also a consequence of the incomplete vocal fold closure. Wagmare et al. also reported an improvement of MPT in patients after RT for early glottic cancer, but the observation time was significantly longer in his group than in ours. ${ }^{8}$

One fifth of our patients was under the age of 56 and one third under the age of 61 . This means that they were still professionally active at the time of diagnosis and treatment. From the patients' point 
of view, it is very important that their voices improve soon after the completion the treatment, allowing them to return to work. Three months after RT, more than one half of the patients had VHI below 19, a cut-point discriminating between normal and pathological voices. In any case, this also means that more than one half of the patients did not feel handicapped by their voice quality. Due to an abnormal voice quality in a great majority of the patients (according to G score) found by the phoniatrician, we suppose that performing professions with higher voice load or demands for higher voice quality would not be possible. We did not have information about the professional voice use of our patients.

The shortcomings of our study are that all of the instrumental examinations could not be performed on all included patients, although this was due to objective reasons. Still, we succeeded in completing them in at least $85 \%$ of the patients. Furthermore, we did not consider the role of RT-related parameters to the voice quality as the total dose and fractionation pattern were rather comparable in all patients. Having information concerning the profession of the patients would also have given us better insight in their capabilities to return to work three months after the RT treatment.

\section{Conclusions}

Voice disorders have an adverse impact on the social and professional life of patients and reduce the quality of their lives. The main reasons for a decrease in voice quality before treatment is the tumor mass affecting vocal fold mobility and causing the irregular free edge of the affected vocal fold. After successful treatment, the tumor disappears and enables more normal, regular and symmetrical vibrations, with more complete vocal fold closure as well as requiring less effort during phoniation. These are the reasons for significant improvements in voice quality three months after the completion of RT. Unfortunately, post-radiation scarring also affects the vocal folds' vibration and negatively influences the voice quality. However, more than one half of the patients in our study expressed minimal voice handicap three months after RT for early glottic cancer, which is particularly important for those patients who are still professionally active.

\section{References}

1. Peeters AJ, van Gogh CD, Goor KM, Verdonck-de Leeuw IM, Langendijk JA, Mahieu HF. Health status and voice outcome after treatment for T1a glottic carcinoma. Eur Arch Otorhinolaryngol 2004; 261: 534-40. doi: 10.1007/ s00405-003-0697-5

2. Mendenhall WM, Takes RP, Shah JP, Bradley PJ, Beitler JJ, Strojan P, et al. Current treatment of T1N0 squamous cell carcinoma of the glottic larynx. Eur Arch Otorhinolaryngol 2015; 272: 1821-4. doi: 10.1007/s00405-0143388-5

3. Agrawal N, Ha PK. Management of early-stage laryngeal cancer. Otolaryngol Clin North Am 2008; 41: 757-69. doi: 10.1016/j.otc.2008.01.014

4. Huang $\mathrm{G}$, Luo $\mathrm{M}$, Zhang J, Liu $\mathrm{H}$. The voice quality after laser surgery versus radiotherapy of T1a glottic carcinoma: systematic review and meta-analysis. Onco Targets Ther 2017; 10: 2403-10. doi: 10.2147/OTT.S137210

5. Lee $\mathrm{SH}$, Hong KH, Kim JS, Hong YT. Perceptual and acoustic outcomes of early-stage glottic cancer after laser surgery or radiotherapy. A meta-analysis. Clin Exp Otorhinolaryngol 2019; 12: 241-8. doi: 10.21053/ceo.2018.00990

6. Aronson AE. Clinical voice disorders. An interdisciplinary approach. $3^{\text {rd }}$ Edition. New York: Thieme Inc.; 1990.

7. Hocevar-Boltezar I, Zargi M, Strojan P. Risk factors for voice quality after radiotherapy for early glottic cancer. Radiother Oncol 2009; 93: 524-9. doi: 10.1016/j.radonc.2009.09.014

8. Waghmare CM1, Agarwal J, Bachher GK. Quality of voice after radiotherapy in early vocal cord cancer. Expert Rev Anticancer Ther 2010; 10: 1381-8. doi: 10.1586/era.10.126

9. Verdonck-de Leeuw IM, Hilgers FJ, Keus RB, Koopmans-van Beinum FJ, Greven AJ, de Jong JM, et al. Multidimensional assessment of voice characteristics after radiotherapy for early glottic cancer. Laryngoscope 1999; 109: 241-8. doi: 10.1097/00005537-199902000-00014

10. Al-Mamgani A, van Rooij PH, Woutersen DP, Mehilal R, Tans L, Monserez $D$, et al. Radiotherapy for T1-2NO glottic cancer: a multivariate analysis of predictive factors for the long-term outcome in 1050 patients and a prospective assessment of quality of life and voice handicap index in a subset of 233 patients. Clin Otolaryngol 2013; 38: 306-12. doi: 10.1111/coa.12139

11. Barsties B, De Bodt M. Assessment of voice quality: Current state-of-the-art. Auris Nasus Larynx 2015; 42: 183-8. doi: 10.1016/j.anl.2014.11.001

12. Jacobson BH, Johnson A, Grywalski C, Silbergleit A, Jacobson G, Benninge MS, et al. The voice handicap index (VHI): development and validation. Am J Speech Lang Pathol 1997; 6: 66-70. doi: 10.1044/1058-0360.0603.66

13. Tafiadis D, Chronopoulos SK, Helidoni ME, Kosma El, Voniati L, Papadopoulos $P$, et al. Checking for voice disorders without clinical intervention: The Greek and global VHI thresholds for voice disordered patients. Sci Rep 2019; 9 9366. doi: 10.1038/s41598-019-45758-z

14. Alexander FW. Micropathology of radiation reaction in the larynx. Ann Otol Rhinol Laryngol 1963; 72: 831-41. doi: 10.1177/000348946307200316

15. Tedla M, Valach M, Carrau RL, Varga I, Profant M, Mráz P, et al. Impact of radiotherapy on laryngeal intrinsic muscles. Eur Arch Otorhinolaryngol 2012; 269: 953-8. doi: 10.1007/s00405-011-1686-8

16. Rubin P, Casarett GW. Clinical radiation pathology. Philadelphia: W.B. Saunders Company; 1968. p. 36-61.

17. Marciscano AE, Charu V, Starmer HM, Best SR, Quon H, Hillel AT, et al. Evaluating post radiotherapy laryngeal function with laryngeal videostroboscopy in early stage glottic cancer. Front Oncol 2017; 7: 124. doi: 10.3389/ fonc.2017.00124

18. Colton RH, Casper JK. Understanding voice problems. A physiological perspective for diagnosis and treatment. Fourth Edition. Baltimore: Lippincott, Williams and Wilkins; 2006.

19. Lombardo N, Aragona T, Alsayyad S, Pelaia G, Terracciano R, Savino R. Objective and self-evaluation voice analysis after transoral laser cordectomy and radiotherapy in T1a-T1b glottic cancer. Lasers Med Sci 2018; 33: 141-7. doi: 10.1007/s10103-017-2361-0

20. Van Gogh CD, Verdonck-de Leeuw IM, Wedler-Peeters J, Langedijk JA, Mahieu HF. Perspective evaluation of voice outcome during the first two years in male patients treated by radiotherapy or laser surgery for T1a glottis carcinoma. Eur Arch Otorhinolaryngol 2012; 269: 1647-52. doi: 10.1007/ s00405-012-1947-1 